\title{
Discussion on the Teaching Model of Subject Participation Based on the Map Teaching Method Taking the Course Reform of Geography of International Trade
}

\author{
Wang Ning ${ }^{1, a}$, Li Zhao ${ }^{2, b^{*}}$, Zhang $\mathrm{Bei}^{3, c^{*}}$ \\ ${ }^{1}$ School of Economics and Management of XI'an Mingde Institute of Technology, Xi'an, Shaanxi, China \\ ${ }^{2}$ School of Economics and Management of XI'an Mingde Institute of Technology, Xi'an, Shaanxi, China \\ ${ }^{3}$ School of Economics and Management of XI'an Mingde Institute of Technology, Xi'an, Shaanxi, China \\ a604381626@qq.com \\ b*nwpulizhao@163.com \\ c*182182932@qq.com
}

\begin{abstract}
With the acceleration of globalization and the implementation of the "One Belt One Road" strategy, our country's economic and trade scale with other countries in the world has further expanded, The deepening reform of economic and trade cooperation puts higher demands on my country's foreign trade talents. International trade geography is a compulsory course for international trade majors that integrates international trade practice and economic geography. Based on the characteristics of students and social needs, independent colleges and universities adopt the subject-participation mode of teaching under the map teaching method to highlight learners' active participation. In the actual teaching process, relying on advanced curriculum theories such as international trade theory and marketing, and guided by geography theory, the goal is to cultivate students' imagination, spatial, and creative thinking skills. Break the boundaries between classes, continuously establish the important position of maps in the teaching of international trade geography and the value of map information transmission, and promote the positive role of spatial information in the teaching of international trade sites. Cultivate the necessary geographical literacy for students majoring in international trade to cope with the challenges of modern and future society.
\end{abstract}

Keywords: Subject participation, Map teaching, Trade Geography

\section{基于地图教学法下的主体参与模式教学探讨 一以国际贸易地理课改为例 王宁 ${ }^{1, a}$ ，李昭 ${ }^{2, b *}$, 张蓓 ${ }^{3, \text { c* }}$}

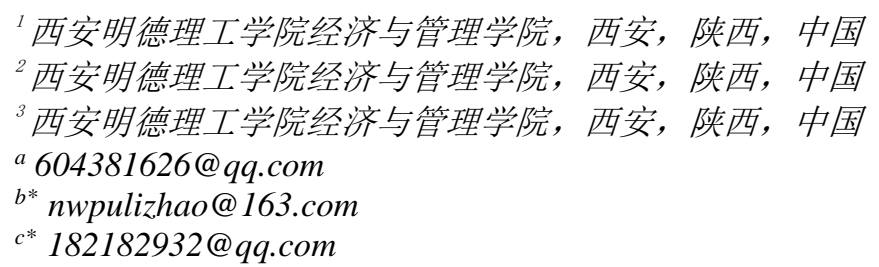




\begin{abstract}
摘要
随着全球化进程的加快和 “一带一路” 战略的实施，我国同世界各国经贸规模进一步扩大，经贸合作的深化改 革对我国外贸人才提出了更高的要求。国际贸易地理作为综合国际贸易实务与经济地理学的一门国贸专业必修 课, 独立院校从学生特点和社会需求出发, 采用地图教学法下的主体参与模式教学, 突出学习者的主动参与性。 在实际教学过程中以国贸理论、市场营销等先行课程理论为依托, 以地理学理论为指导, 以培养学生想象思维 能力、空间思维能力及创造思维能力为目标, 打破课际界限, 不断确立地图在国际贸易地理教学中的重要地位 和地图的信息传输价值, 推动空间信息在国际贸易地教学中的积极作用, 培养国际贸易专业学生必备的地理素 养，以应付来自现代及未来社会各方面的挑战。
\end{abstract}

关键词: 主体参与; 地图教学; 贸易地理

\section{1. 意义}

\section{1 教育背景}

传统的国际贸易地理教学侧重于对经济地理事 物特征及其空间分布状况的讲述, 图像系统在国际贸 易地理教科书中一直处于 “附图” 或 “插图” 性质的 辅助地位。地图作为记载、传输地理信息的特种文化 工具, 因具有信息传输、信息载体、地理认知等特征, 被称为 “地理的第二语言”。在国际贸易地理教学中, 对于已经具备一定国际贸易理论基础的高年级学生, 应把地图的应用列为培养学生技能的主体要求。地图 教学法通过让学生熟知各地资源禀赋差异, 了解世界 主要国家和地区的产业布局、地域经济特征、对外贸 易流向及动态趋势, 综合掌握贸易地理格局和流向, 有效地传授地理知识, 形成地理技能, 提高学生地理 思维的能力, 改变长期以来学习与工作两套系统二元 割裂的状态, 让学生在校期间不但获得必要的专业理 论知识, 更重要的是为学生外贸实践工作打下坚实的 基础。

\section{2 现实背景}

随着全球化进程的加快和 “一带一路” 战略的实 施, 我国同世界各国经贸规模进一步扩大, 《国际贸 易地理》作为一门将地理与经贸相结合的国际经济与 贸易专业基础课程, 让学生在了解各个国家及地区自 然地理和人文地理特征的基础上, 掌握世界各个国 家、地区商品市场之间的地理分布情况及供求、交换、 运销状况, 充分理解国际贸易中商品流通与市场规律 和特点对于国际贸易的影响, 该课程涉及面广、内容 丰富、综合性强, 不但具有地理空间区域性及差别性, 而且拥有经贸社会特性和动态特点。经济合作的进一 步深化对外贸人才也提出了更高的要求, 对《国际贸 易地理》课程进行教学模式的改革与探索, 以适应我 国对外贸易市场的多元化需要具有非常重要的意义。

\section{2. 文献综述}

在国际贸易对经济贡献度不断增加的背景下, 国 际贸易地理作为培养多元化国贸人才的一门专业课, 同时又作为经济地理学的一个分支, 是融合国际贸易 理论和地理知识的综合性课程, 具有很强的知识性和 实践性（蒋江林，2018）。但目前各大高校在国际贸 易地理课程的教授过程中普遍存在教学方法单一、教 学模式单调、教学设备简随等问题。采用地图教学法 下的主体参与教学模式, 强调师生共同参与教学活 动, 以实现课堂教学效率最大化。

肖雁飞认为各种布局关系、资源 流向、交通线 路等国际贸易地理知识可以在地图上一目了然, 比文 字叙述更准确、更直观, 有利于学生直观掌握国际贸 易地理知识。因此我们在国际贸易地理课堂教学中充 分利用地图表达的直观性、综合性特点, 以图为纲启 发引导学生, 灵活掌握学科要点。

\section{3. 基于地图教学法下的主体参与模式教学模 式设计}

\section{1 采用地图教学法下的主体参与教学模式的 必要性}

我院国际经济与贸易专业在厚基础、宽口径、重 素质的人才培养模式下, 目前已成为经管学院的成熟 老牌专业, 在校学生凭借扎实的理论基础参加全国国 际贸易精英挑战赛也屡创佳绩, 但该课程的教学仍采 用传统的教学方法一一以教师为主体, 以教室为中 心, 以知识灌输为基本方式。这种单一的教学模式极 大地抹杀了学生的学习热情, 同时该课程涵盖内容广 泛、知识点零散、学生学习难度大。单纯的教师讲授 方式远不如图文结合、案例分析、小组探讨、实际演 练及成果展示等方式下的教学效果好。 


\section{2 项目建立目标}

\subsection{1 培养想象思维能力}

想象是在人脑中对已有表象进行加工改造而创 造新形象的过程, 地图是地理信息的重要载体, 是培 养想象思维的重要手段。地理教学的知识范围广泛而 复杂, 一个地理问题包含了诸多的自然要素与各种人 类活动之间的联系, 但这种联系不是盲目的, 而是具 有一定规律的, 以图为纲的国际贸易地理教学, 让学 生通过观察现象、分析现象、形成并想象出这些地理 事物之间的联系。

\section{2.2 提高空间思维能力}

空间认知和定位能力的培养与提高是一个缓慢 而持续的过程, 欧美等国家在对学生的空间定位能力 的培养上注重培养学生运用地理图像的综合能力。我 们传统的教学模式使得学生用图意识薄弱, 仅将地图 作为理解文字的辅助性工作, 同时孤立的看待一幅 图, 没有充分发挥地图综合性、区域性及实践性的优 势。随着互联网的发展, 地图教学方式也发生了变化, 开始由单一的课堂教学转向课外和网络等多样的教 学方式。

地理图像系统是国际贸易地理教材的重要的组 成部分, 在学习过程中, 应该引导学生将课本文字系 统内容与图像信息有机地结合起来, 运用地理图像构 建空间概念, 充分运用课本上的图像资料 和地图册, 养成良好的读图、用图习惯, 这是构建空间概念的重 要途径。读图、看图可使 学生形成初步的空间概念, 而填图、绘图能增强学生学习地理知识的兴趣, 强化 空间概念的形成, 而空间思维的形成, 有利于理解地 理分布下导致的贸易格局和流向。

\subsection{3 开拓创造思维能力}

创造思维是指根据问题提供的信息, 利用已有的 知识经验, 多角度、多侧面开拓思路, 揭示客观事物 的本质特征和内在联系, 从而获得新颖的思维成果。 地图教学法通过学生的发散思维和知识迁移能力, 利 用地图进行广泛的想象和巧妙地组合, 达到思维的新 境地。全面的发展的观点分析并解决问题。

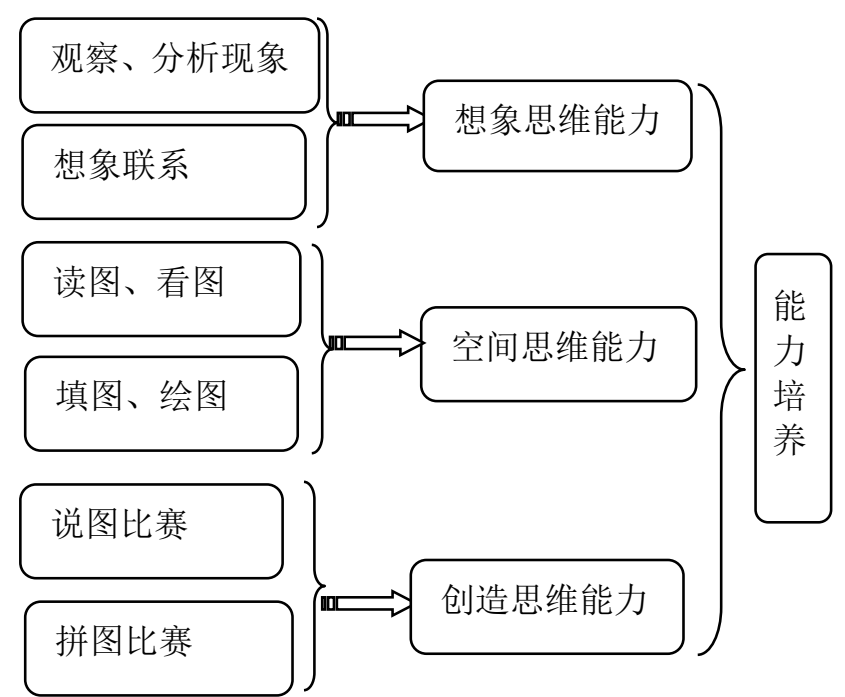

图 1: 地图法在《国际贸易地理》教学中的能力培养

\section{3项目研究思路}

\section{3.1 改革教学模式，倡导主体参与}

“主体参与” 的教学模式强调以学生为主体、以 学生发展为中心的教育观念下, 强调 “参与”、“互 动”、“合作” 的教育精神。教师打破教材章节界限, 重新设计教学内容, 采用主题教学、小组讨论、情景 设计等方式引导学生主动提问、自主寻求答案, 不断 激发学生参与感。此种教学模式不仅充分发挥学生自 身主体参与积极性和能动性, 挖掘其潜能并释放出 来, 同时打破传统的教师向学生单向传递信息的模 式, 不断向多项信息传递模式转变, 即学生与教师, 学生之间都可以传递信息。（见图 2)。

主体参与的教学模式将教师的作用由 “教” 向 “导” 进行转变, 教师通过参与、设计、引导、梳理、 点拨、示范、质疑、释疑、辅导、生成、指导、督促、 检查、评价等教学行为调动学生学习积极性和课堂参 与性, 激发学习兴趣, 培养创新精神。课后通过让学 生以团队协作的方式完成小组任务, 深化学生协作精 神、交流技巧与情景再设计的能力。

\section{3.2 创新教学手段, 深化地图教学法}

国际贸易地理课程中的地理教学指在学校范围 内, 任课教师以国际贸易专业大二国际市场营销、国 际贸易理论与实务为先行课程理论为依托, 以地理学 理论为指导, 要求学生在掌握国际贸易地理理论知识 的基础上, 获取、分析、处理和应用地理图像信息, 培养国际贸易专业学生必备的地理素养, 以应对来自 现代及未来社会各方面的挑战。 


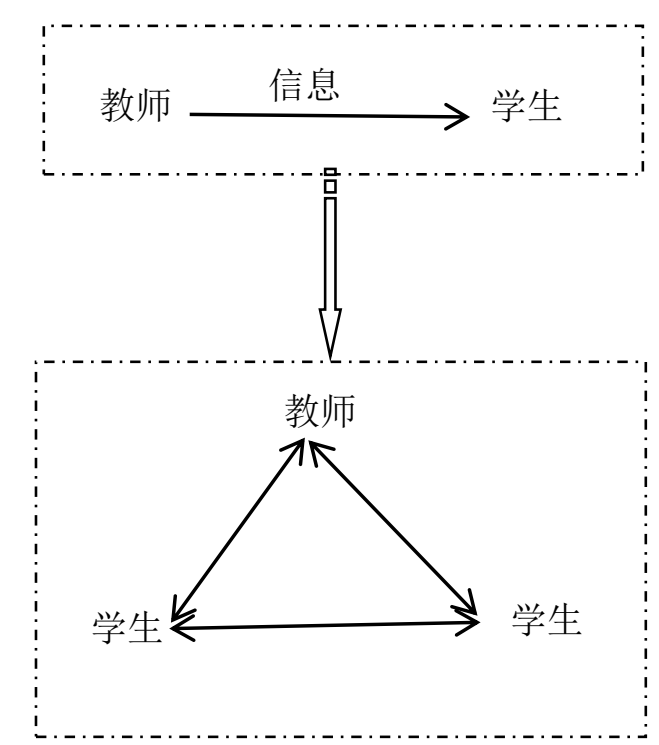

图 2: 主体参与的信息传递模式变化示意图

地图通过自身的符号系统, 可以将地理事物及国 际贸易活动进行最大限度的浓缩, 地图教学法试图让 学生通过阅读地图, 把地图符号所代表的的地理事物 名称和分布, 联想到与事务相关的国际贸易活动。如 在讲授国际贸易运输方式中的海运时, 通过航线了解 位于不同区域的的港口的自然条件和运输条件的差 异，同时联系国际贸易实务中的保险条款，制定合适 的海上货物运输保险的承包范围、货运保险条款等。

\section{4. 基于地图教学法下的主体参与模式教学改 革的创新点}

\section{1 打破课程边界, 重建课程体系}

课题组通过对调查问卷进行分析与总结, 剖析存 在的问题及成因, 着力解决了该课程教学中存在的 “重理论传授轻技能培养, 重知识掌握轻实践应用” 问题。以图为纲, 打破课际界限, 将国际贸易地理与 市场营销、国际贸易理论与事务、国际贸易单证等课 程充分关联, 通过不同课程的内容渗透, 在丰富课程 内容的同时让学生了解一个更为真实地国际贸易环 境。最终通过该门课程的学习, 不仅了解一个国家或 地区的自然环境、人文环境、工农业产品的分布以及 该国在国际贸易中地位, 以便我们更好的开展外贸活 动。

\section{2 转变教学理念, 重视能力培养}

主体参与可以最大限度地关注到每一位学生的 课堂问题, 通过 “讲-学-练-评” 实现师生互动, 提 高课堂整体效率。采用发散型思维, 由教师作一般性 介绍, 然后鼓励学生畅所欲言, 引导学生由传统的被 动式学习转变为主动思考、积极学习, 培养学生的想 象思维能力、空间思维能力和创造思维能力。

\section{5. 基于地图教学法下的主体参与模式教学评 价}

地图教学的目标是正确引导学生, 通过读图并想 象将图中蕴含的信息提炼出来，服务于国际贸易活 动。但这种能力的培养与提高是一个缓慢而持续的过 程, 在实际教学中倡导主体参与, 通过学生主动参与 来构建知识, 分发挥学生的积极性和能动性。

地图教学法下的主体参与的教学模式的实施一 方面解决了专业课课时有限的问题, 另一方面在教学 中充分实现教师与学生均为课堂教学主体, 强调师生 互动, 共同参与教学活动。多角度培养国际贸易专业 学生必备的专业素养, 以应付来自现代及未来社会各 方面的挑战。

\section{6. 结论}

本项目立足于国际贸易实际工作需求，将地图融 入到本科理论教学过程中, 以图为纲提高学生地理思 维能力。在教学过程中将多门相关课程的融合, 以多 点植入的方式将国际贸易理论与实务、国际市场营销 等课程内容相结合, 保证了课程内容的丰富性和学科 交叉性, 全方位全视角地培养学生贸易能力、提升学 生实践操作能力。

\section{项目基金}

本文为西安明德理工学院教育教学改革研究项 目《过程导向和任务驱动的情景模拟教学模式探讨一 以金融服务礼仪课改为例》的阶段性成果之一。

\section{REFERENCES}

[1] Jiang jianglin. "Subject participation and hidden stratification" research on the Application of Teaching Mode in the Course of "International Trade Geography". Think Tank Forum, vol.44, pp. 235-236, 2018

[2] Xiao yanfei. The Map Teaching Method of the Course "International Trade Geography". Theory and Practice of Contemporary Education.vol5, pp70-71,2013

[3] Wu guangxia. Pay attention to map teaching and Cultivate thinking skills. Teaching and management. vol3, pp66-67, 2003

[4] Gui xialiu. Research on Map teaching under new concept in Geo-Curriculum Standard in senior high school period.vol23,pp23-27,2004

[5] Sun jun.Qiu yanping. Infiltration teaching of international trade geography in international trade practice. The Science Education Article Collects.vol12, pp57-58,2017 